\title{
A FEW HISTORICAL DATA OF THE MODERN SCIENCE OF LANGUAGE.
}

$\mathrm{N}$ retracing the historical phases of the modern science 1 of language, we are confronted at the outset of our survey by two singular facts: first, that the theory and the technical knowledge of language had remained stationary and unchanged from classical times to the second decade of the nineteenth century; and by the other equally startling fact, that all the achievements of the modern science of language and of comparative philology, have been accomplished within the lapse of only a few decades of the past century. It must be added that the edifice of the science of language that has been reared by the philologists of the nineteenth century, is no mere accumulation of disconnected material, but, by its basic principles, must be regarded as a complete and finished structure. Within the first decade of the present century, accordingly, it may not seem altogether inappropriate to recall to mind, first, the causes of the obstacles which so long impeded and retarded the study and the correct conception of language; and next, briefly to review the progressive stages, which, as it were, irrespective of their duration have led up to the erection of the modern science of language within the narrow space of a few decades. We shall not incur the risk of exaggerating the intrinsic value or the vast bulk of the work that has been performed. In this respect the reader may at once be referred to Prof. Theodore 
Benfey's exhaustive volume, published in I869 at Munich. Germany, and entitled: History of the Science of Language, and of Oriental Philology in Germany. The volume in question exclusively relates to work done in Germany by German philologists, and yet, the multitude and variety of subjects must fill us with astonishment. If we should only undertake to write down the names of all those devoted workers in the field of language and philologyin the words of an ancient Sanskrit sentence:- "soon the chalk would drop from our hand!"

That Germany, during the nineteenth century, should have produced such a prodigious number of specialists in this department of research was due to many local causes. Notwithstanding the incontestable fact that German philological scholarship received a vast supply of valuable materials from abroad-from England, France, and other countries-German philologists still may claim the modern science of language as a native German product, or as distinctly a German science.

The intrinsic hindrances to the creation of a genuine science of language have mainly arisen from the philosophical systems (particularly metaphysics and logic) which, during so many centuries, molded and warped the minds of Europe. Throughout the European middle ages theoretical philosophy had conceived the notion of an $a b$ solute speech-form, and, consequently, it proclaimed the absolute, substantial unity of all human languages.

On the other hand it is generally known that the theoretical philosophy of the past was generally applied to the so-called metaphysical categories-to the abstract notions of being, essence, matter, force, cause, effect, phenomenon, etc.; while logic taught the most general forms of all scientific thinking.

But this abstract philosophy of the middle ages ignored or remained indifferent to the important fact that within 
the independent domain of objective reality there is found a parallel series of sciences, viz., a science of nature, and a science of the human spirit,-the science of history, or philology in the broadest sense of the term.

The science of nature and the science of the human spirit follow their own independent laws. Nature and mind do not presuppose respectively the existence of an abstract philosophy of nature, or of an abstract philosophy of history. This would only result in a conflicting dualism-the dualism of theory on the one hand, and of empirical science and of history on the other. It was this very dualism which asserted its supremacy when the abstract philosophy of the middle ages persisted in applying its own exclusive, constructive theories to the objective phenomena of reality.

This dualism was a spontaneous creation of the middle ages, harmonizing perfectly with the dogmatic and scholastic methods of the period. During the middle ages this dualism revealed itself not only in every theorizing tendency of the human mind, but even in the entire organization of social life,-in the form of an antagonizing contrast of nature and mind; of earthly existence, and of life in the beyond; of Church and State; of State and individual; of life external; and of a mystic, inward life.

Under conditions of this kind, any science of nature was impossible, because nature was ignored, and despised.

This fictitious dualism, however, had been unknown to classical Greek antiquity. I can only mention here that the technical terms which are still employed in describing the varied aspects of this dualism-terms like " $a$ priori," "a posteriori," "synthesis," "analysis," "syllogism," "induction," and so forth-all of these, certainly, were used by Aristotle, yet with this important difference, that the Greek philosopher employed these terms in a sense that was entirely different from the significance which later 
was imparted to them by the scholastic philosophy of the middle ages. During the middle ages, only logic could rise to the height and dignity of a science, because the Christian dogma and system of theology found that logic proved the most serviceable hand-maid of all arbitrary constructions.

Probably every one is well acquainted with the fact that Lord Bacon, in his Novum Organum, was the first who attempted to combine the hair-splitting subtleties of scholastic logic with the creation of a more dignified science of nature. But we must also recall to mind that almost at the same time there arose the French philosopher, Descartes, who, starting from the principle: "cogito, ergo sum," sought for certitude in the cognition of being; while being itself is supposed to result from thinking.

This meant the same as to restore the old conflicting dualism of empiricism and of theory even more pointedly than before; because, with Descartes, a priori no longer meant "from the cause," but "from pure thinking" unsupported by experience.

When, at a later date, Kant proposed the doctrine that experimental knowledge, in order to be possible, must be preceded by certain a priori cognitions, this German philosopher admittedly imparted a new impulse to philosophy; and it is well known how he himself defined and limited these categories of all our cognitions. Our experimental knowledge forms a compound combination of what we receive through our sensual impressions, and that which our innate power of cognition yields from within. As such this doctrine did not involve a dualism proper; but, nevertheless, it soon furnished an occasion for a revival of the old dualism when Hegel maintained that he had found that which Descartes had sought for, to wit, absolute certainty;-a knowledge of being that was as certain as thinking. Hegel contended that not only the abstract $a$ 
priori forms of our cognitions, but also the form and contents of all being, are found within the mind, and that mind itself furnishes these contents.

I have here mentioned these past philosophical systems only in order to show that in reality they were incompatible with either a correct conception of language, or with the creation of a genuine science of language.

Philosophy could only conceive language as substance -a "thing-in-itself" (Ding an sich), as it was called. But the modern science of language has proved the affinity of language with the whole evolution of humanity in history; and therewith, the genuine science of language, also, has done away with absolute methods and the $a$ priori definition of language of past philosophical systems.

It is generally admitted that during the earlier decades of the nineteenth century no philologist has worked with greater energy against that philosophical conception of speech than has Dr. H. Steinthal, the late professor of the general science of language in the University of Berlin, Germany; of Old Testament interpretation at the Hebrew High School of the same city; and (together with Professor Lazarus) the editor of the German Zeitschrift für Völkerpsychologie. In one of his earliest works, entitled: Die Sprachwissenschaft Wilhelm von Humboldts und die Hegelsche Philosophie, (published in 1848), Dr. Steinthal, as interpreter and emendator of von Humboldt's philological ideas, has at the same time paved the way for a series of important works in the same line of research. Of these preparatory works I shall mention Dr. Steinthal's dissertation "On the Reciprocal Relations of Philology, History and Psychology" [Philologie, Geschichte und Psychologie in ihren gegenseitigen Beziehungen], delivered before the Convention of Philologists at Meissen, in the year 1863; further, his "Classification of Languages" [Die Classification der Sprachen]; and his "Characteristics of 
the Principal Types of Language-structure" [Characteristik der hauptsächlichsten Typen des Sprachbaues, Berlin, I860].

In the following remarks, in order to obtain a comprehensive survey of the historical data of the modern science of language, it will prove useful to recapitulate a few of the philological thoughts which the above works suggest to the modern student of the science of language.

Philosophy, at all times, had conceived a fictitious, $a b$ solute speech-form, and, hence, the substantial unity of all languages. From this abstract construction it followed that still in the second decade of the nineteenth century the historical grammarians had scarcely yet advanced beyond the limits which the Greeks and Romans had formerly attained. The knowledge of the historical grammarians was yet limited to the two classical languages. The classical languages were opposed to the languages of the Orient, and by these were understood only the Semitic languages, probably in deference to Old Testament literature. This narrow treatment of language, moreover, tallied with the purely external, mechanical theory of language, which also still prevailed in the second decade of the nineteenth century.

The author of this mechanical theory was Friedrich Adelung, a German scientist residing and writing in Russia. Adelung is still remembered as the author of a work entitled Mithridates, which he intended should be a kind of universal grammar of all languages of the globe. The classical grammar was supposed to suit the form of any national language; but even to Adelung the value of this universal grammar had no direct bearing upon the deepest problems of speech, such as the origin, nature and classification of languages. It was merely imagined to afford an external advantage, i. e., for the geographical distribution of nations; and, in harmony with the pre- 
vailing philosophical systems, the author concludes that all languages are built on nearly the same plan, and that it is idle to dispute about the relative excellences of any language, because time, circumstances and civilization will improve any language. In this system there is no question of classification proper, but only of a geographical line of languages, beginning with the monosyllabic languages of Eastern Asia, and with the polysyllabic languages, extending through Central and Western Asia into Europe. Even long after Adelung's time, this is still a widely popular theory of language; and, withal, the only notion of language understood and entertained by many persons of average culture in our own day. Adelung's theory, however, could not satisfy any earnest student of language. Soon after Adelung there arose a new school of philologists, who assumed a marked antagonistic attitude toward the philosophical theories of the past. When Eichhorn proposed the genealogical grouping of languages, by including the Hebrew, with the kindred languages, there begins a new independent era of linguistic science.

This was the first step in the right direction; because the aim of modern comparative linguistics is, precisely, classification according to families and tribes of languages. Comparative linguistics of this kind, however, have their limit, and by themselves are far from sufficient; for when there has been performed the task of comparing and distributing particular languages into families of kindred tongues, these linguistic groups have yet to be characterized, according to their inward differences or diversities of form. This cannot be done through the mere proof of the affinities of these languages. The genealogical or genetic classification, nevertheless, remains the necessary basis of every attempt at a scientific classification of languages, although the genesis of languages must be rigorously kept apart from that of races and nations. From 
the genesis of languages, absolutely, the origin of nations themselves can not be absolutely inferred, nor, on the other hand, does the relation of languages to ethnology represent the most important side of the science of language. Although language so long continued to be regarded as a mechanism, there appeared, as early as the first decade of the nineteenth century, a German thinker who cautiously ventured to assert that language was not merely a mechanism, but rather an organism. This thinker was Friedrich Schlegel. In his work: Weisheit der Inder ("The Wisdom of the Hindus") we find for the first time, entirely new ideas concerning the nature of language, in striking contrast with the accepted theories of the philosophers; and the Germans, accordingly, claim that with Friedrich Schlegel the modern science of language must be said to begin. Schlegel wished to classify languages. and to this end he created three main divisions: languages without inflection, agglutinative languages, and inflected languages. In the first class the particles that modify the sense stand entirely apart, i. e., they are words independent of the root. In the second (agglutinative) class, grammar is entirely made up of suffixes and prefixes, which are everywhere easily distinguishable and still preserve to some extent their original significance, such as of plural, of past or future action; and yet, these agglutinative particles have already begun to amalgamate, to coalesce with the word. Schlegel regards both these classes as inorganic and contrasts them with the third, the inflected languages, which he calls the really organic or organized class.

In Schlegel's own day these novel views signaled an important innovation in the methods of linguistic research. $\mathrm{He}$ had thus discovered that an enormous distance intervenes between the inflection of the Indo-European languages and the technique, or means of creating grammar, 
employed by a number of other races; and he had understood that the Indo-European inflection could not be explained from any purely mechanical process. But, on the other hand, he had not attained to a clear intuition or perception of the nature of this difference. He only felt that it was the result of an inward process; but he grows vague and obscure when he seeks to explain it. Thus his conception of language assumes a mystical aspect. He maintains, for example, that in Sanskrit and in Greek each root is really what it stands for, like a living germ; but, as Dr. Steinthal remarks, to convert a mental activity into an immediate process of nature is to fall into crude mysticism.

A. W. Schlegel, Friedrich's equally distinguished brother, in his remarks on the Provençal language and literature has reproduced the aforesaid triple classification, perhaps, in a clearer form. A.W. Schlegel, within the third or inflected class, further gives an interesting sub-division which he calls synthetical and analytical languages. Synthetical languages use inflected forms where analytical languages only employ prepositions, pronouns and auxiliary verbs. The Greek and Latin are examples of the synthetical kind; while English and the languages derived from the Latin have an analytical grammar. The Teutonic languages form an intermediate class. The analytical languages have been evolved at different historical periods from the synthetical languages. A. W. Schlegel maintained that the ancient synthetical languages enjoyed a superior excellence. The highest praise that can be bestowed upon our modern languages is their perfect adaptation to the actual needs of the human mind; while the most signal advantage of the ancient classical languages consists in the much greater freedom they enjoy in the arrangement of the words within the sentence. Here, they satisfy the cravings of logic, and ensure clearness by so- 
norous and accentuated inflections. Through an endless variety of phrases and by entwining words with exquisite taste, the speaker, writer, and the inspired poet, were able to impress the imagination and sensibility of others with an ever novel charm. On the other hand, the modern languages are severely bound to the rules of logic, since, while having lost the greater part of the inflections, they are compelled to designate the relations of ideas by the position, which the words occupy in the sentence. A. W. Schlegel, in conclusion, makes the following striking remarks on the synthetical languages: "They belong to another phase of the human intellect. In the synthetical languages there is revealed a more simultaneous action, and a more immediate impulse of all the faculties of the soul, than in any of our modern, analytical languages. The analytical or modern languages are controlled by reason which acts apart from the other faculties, and hence, renders a better account of their operations. I believe that in comparing the genius of antiquity with the spirit of modern times we shall discover a contrast entirely similar to that which exists between the two classes of languages. All the great creative syntheses of history were the work of a remote antiquity, while perfected analysis was reserved for modern times."

A few years later Prof. Franz Bopp successfully turned these inspired intuitions and direct perceptions of both the Schlegels into a genuine practical benefit to linguistics and philology. Professor Bopp takes Friedrich Schlegel particularly to task for his contradictions, mysticism, and, above all, for his lack of historical, technical knowledge of languages. Professor Bopp, in principle, readily admits Schlegel's conception of language as organism; and, as well, the scientific value of a natural classification such as Schlegel had aimed at; but thereupon Bopp himself in his monumental work, $A$ Comparative Grammar of 
the Indo-European Languages, furnishes an essentially modified classification: "First," he says "there are languages with monosyllabic roots, devoid of any capacity of composition, and hence, without organism and without gramniar. To these belongs the Chinese, in which everything is still the naked root, and in which the grammatical categories, and all collateral relations, are mainly understood from the position of the roots in the sentence. Secondly: Monosyllabic languages which are capable of composition and which by this means almost entirely obtain their organism, their grammar. To these belong languages that have an affinity with Sanskrit, and all other languages not belonging to the first class, except the Semitic languages. The Semitic languages, apart, form the third class. The Semitic languages create their grammatical forms not only through composition, like the second class, but also by means of a purely inward modification of the roots."

From this classification it will be seen that Professor Bopp starts from the technique of language, that is, from the means by the aid of which language creates grammar, and employs it for the designation of the categories. This technical point of view henceforth constitutes the essential element which must be taken into consideration in all attempts at classification of languages. It is to Prof. Franz Bopp's enduring honor that he created the modern historical grammar. His linguistic and philological work has. of course, been extended and perfected by a host of later scholars; but, in the principle which pervades and controls his methods, Franz Bopp can scarcely be superseded. To the historical grammarians, accordingly, belongs the credit of having performed the main bulk of all the linguistic and philological work of the nineteenth century. From this time, the valuable creations of the modern science of language have been poured forth, every year of the cen- 
tury. The true principle of linguistic research having once been discovered, the progressive advance of the science of language was no longer dependent on the duration of time. In order to obtain a survey (if only superficially) of that prodigious intellectual activity, it will suffice to glance at European linguistic catalogues, like Trübner's Bibliotheca Sanscrita, exclusively relating to the department of Sanskrit literature; or to turn over the leaves of such German philological reviews as the Zeitschrift fïr die Kunde des Morgenlandes; or the Zeitschrift der deutschen morgenländischen Gesellschaft,-every page of which casts a flood of light on the history, the religions, and the philosophical systems of every nation of Asia.

But all this arduous work performed by the historical school is far from completing the task of the science of language; because the theory of the historical school, by conceiving language as an organism, soon found it necessary to connect linguistic study with the kindred sciences of history and psychology. Language, as Dr. Steinthal observes, taken by itself and treated historically, only represents a partial, one-sided revelation of any national mind. Any purely technical investigation of language, in order to be philological and to obtain historical significance, must bring the historical evolution into contact with numerous other manifestations of the mental life of a race or nation. In this sense Grimm's Grammar of the Germanic Languages is quoted by Professor Steinthal as a luminous instance of a broad, philological treatment of language, because, on the one hand, Grimm limits his technical research to the historical grammar, while, on the other, he extends his investigation to all the clepartments of literature-to religion, jurisprudence, social institutions, to all the intellectual achievements of the Germanic nations. In this sense Grimm became the true founder of a racial, Germanic philology. But besides Grimm's Germanic philology 
there are other national philologies, like those of the Romance, Slav, and other linguistic groups. The investigations of these, also, include the literatures, institutions, and the whole intellectual activity of those nations; whence it must follow that the exclusively historical method applied to each group will not be sufficient. We are prompted to a deeper study of the relations of the science to several other sciences. In a broad sense, philology thus becomes the science of the universal human mind, as manifested in the varieties and differences of all the national philologies of the globe. In order to understand and to create ideas, philology must think-must be a thinking science. Philology becomes an historical science only through combining together perception (Anschauung) and thinking. In philology perception and thinking in a definite form are revealed as interpretation and critique. Interpretation seeks to understand the objects of cognition, while critique measures particular objects according to universal standards by comparing, judging, and arranging the successive stages of any evolution. In this sense philology must be said to perform a double task: first, from an historical and philosophical point of view, it endeavors to understand the evolution of the universal human mind; and thereupon it applies the laws of that evolution to the phenomenon of speech, by investigating the origin and nature of language. In fact, considerable time before Franz Bopp, several European and American philologists had already undertaken to write so-called "Philosophies" of language, purporting to explain the origin and nature of language, the relations of speech to thought, to logic, and so forth. But, when we recall to mind the dualistic philosophy of the middle ages and that same dualistic tendency again, from Descartes, through Kant, to Hegel, it was to be expected that those "pseudo"-philosophies of language would result in some of the the most erratic and arbitrary elaborations 
of the European mind-of that European mind which the Frenchman Rénan, perhaps too severely, has somewhere characterized as, theoretically, the most gullible among the racial minds of the globe.

Without entering into a detailed discussion of the several divergent theories, let me simply remark that in Germany the so-called "younger school" of comparative grammar, founded by Schleicher, maintains that language is purely a natural organism; and that the science of language belongs to natural history. This short-lived school, however, relapsed into the empty formalism which earlier had been set forth by the German philologist Becker. In this connection it may suffice to recall to mind that although Schleicher and other distinguished modern linguists (including the late Prof. Max Müller, and in America, Professor Dwight Whitney) have doubtless rendered important service to the science of language, it does not follow that they always proved to be profound or very consistent thinkers in formulating their theories on the origin and the nature of language. As regards America, such singularly one-sided treatises as Professor Whitney's Oriental and Linguistic Studies, and his Study of Language, have not failed to produce a painful impression upon the European adepts of the historical school founded by Prof. Franz Bopp. Those who may have read Dr. Steinthal's Antikritik, written in refutation of Professor Whitney's philological views, will easily understand the the wide divergence between American and German philological ideas. In attributing to language stratifications, phonetic decay, dialectic regeneration etc., as to a solid substance, the writers of self-styled "Philosophies" of language forgot that even Hegel himself had written in regard to Spinoza that "substance must be resolved into a process."

Among the men who in the early decades of the nine- 
teenth century imparted a novel impulse to the theoretical investigation of language Wilhelm von Humboldt particularly deserves to be mentioned as one of the most original thinkers of modern times. On this occasion I can only refer to his last work about the Kawi language-an extinct language on the Island of Java. In his intensely thoughtful introduction to this work, while discussing the existing varieties of human languages, Humboldt applies to the domain of language those same ideas which he had earlier applied to the whole intellectual evolution of man. More than all others, Humboldt was impressed with the individual character of the evolution of the human mind. Throughout history in the laws and the institutions of the State, in the sciences and arts-everywhere he meets with individual characters, individual achievements. As a result, he views history mainly through nature's distribution of mankind into races and nations; and, moreover, he conceives each nation as a collective individual. But because national differences are most markedly expressed precisely in the forms of their respective languages, he finds it necessary to investigate also the nature of all human utterance. He regards each single language as a definite, individual expression of some national characteristic; as some exclusive, national conception of earthly existence; or, as he calls it, "eine eigenthümliche Weltansicht." Still, as he proceeds, Humboldt himself is forced to acknowledge that even this individual conception is yet far from satisfying the innate cravings of the human spirit. Within all men-individuals as well as nations-there exists a foreboding of the universal, a craving for totality. This obscure longing for totality immediately accompanies our sense of individuality itself; and it even grows more intense in the same ratio as our sense of individuality is strengthened. Individuals, according to Humboldt, are but the external manifestations of the particular evolutions of the 
universal vital principle, or energy, which he terms "das innere sich in seiner Fïlle frei cntwickclnde Lebensprincip. But this vital principle, this center, is entirely unknown to us. The unknown, abstract totality remains but an aspiration-an unsatisfied longing. From these ideas we perceive that Humboldt himself, for a moment at least, relapses into the dualistic mysticism of the abstract "thingin-itself."

By retaining this abstract totality, Humboldt accordingly is unable to reach an organic classification of languages, but only obtains a classification by differences of degrees. Prof. H. Steinthal, however, points out that Humboldt himself, in the progress of his deep investigation, unconsciously breaks through the dualism and solves the apparent conflict between the individual phenomenon and the craving for totality. Humboldt had remarked that in the historical evolution of the universal human mind we may discern a double kind of progress. First, there is the slow, almost mechanical advance in a straight line, as it were, in which the earlier is ever the cause of the later, the subsequent phenomenon. But from time to time, by suddenly imparting new impulse, the original, sluggish movement is not only continued forward, but accelerated and intensified; as, e. g., when within any national groups there arise more perfect laws and improved religious or social institutions-all of which things are seen throughout history to have been mainly the work of individual men of genius. These men, by their inborn creative energy and will-power, were able to transform the old elements into a more expanded human activity, no longer purely individual and local, but often of a broader or even universal value and significance.

This actually takes place within the historical evolution of languages. Humboldt asks, "who creates language?" And he answers that within the race or nation, language 
is the work of all collectively, and at the same time of each single individual within the nation. But here also we find that in each nation there are periods when this collective linguistic work of the masses suddenly soars to unexpected heights, or is transformed by the higher creative energy of individual men whom we usually call men of genius. In poetry and in prose the individual efforts of these men at all times mark the creation of the national literatures of the world. The traditional elements which they employed were not strictly the causes, but merely the conditions of their creative efforts. The true causes must be sought for in their own higher creative energy or power of will which transformed the previous elements into a broader ideal for the benefit of their own people and of humanity at large.

During these creative periods of their national literatures, we thus perceive that the respective languages display indeed their most exclusive, individual, national forms; yet, at the same time, that both in form and contents they assume a universal human value and signifcance. It is precisely in this sense that we call the Greek and Latin the "classical" languages; and in this sense, also, the word "genius" simply means the creative energy of individual personality rising to the heights of totality. of universality.

The arbitrary a priori doctrine of the substantial unity of all languages had for ages closed to philology every avenue of thought, of critique, and the creation of new ideas. On the contrary, the modern science of language, while refraining from absolute methods, investigates language mainly as a natural psychic process. Metaphysics and logic remain the sciences of general principles; but within the domain of objective reality, of nature, the study of language, like other natural sciences, requires a special, mediating, or auxiliary science. This mediating science, 
the study of language (together with philology and history) will clearly find in psychology. As the natural scientist refers the totality of natural objects to one principle, i. e., to matter, so the psychological philologist who investigates the historical evolution of the human mind refers all the forms of that manifestation to the particular principle which we call spirit, soul. Psychology above all is an experimental science and as such is not concerned about the reconciliation of matter and soul. The natural scientist understands by matter the totality of the laws which govern material phenomena; and, likewise, soul to the psychological philologist denotes the totality of the laws which control spiritual or mental manifestations. The laws the soul follows remain the same whether we prefer to regard them as the laws of certain cerebral functions, or as the laws of some immaterial soul-substance. Psychology, accordingly, is purely a mediating and auxiliary science to philology for the investigation of the laws which are discernible in the mental evolution of humanity; but, whether the origin of speech must be referred to an unconscious activity or to innate faculties, is a problem entirely apart.

The English thinker John Stuart Mill, in his System of Logic published in the year 1843 , was one of the first to propose what he called a "Social Science"; and in the same book also a "Science of National Character." The English thinker would probably have realized his purpose, and would have opened up a much wider field of research, if he had clearly understood the relations of philology to history and to psychology, as well as the fact that in this broader sense philology is history. Within philology, from the point of view of the inward factors of the human mind, the history of races and of nations becomes the history of the organization of states, of national constitutions, of commerce, of private life, and of the arts. While the 
outward division into races and nations marks a difference, on the other hand the mental evolution reveals a sort of unifying tendency. A higher degree of racial and national self-consciousness, therefore, becomes the true lever of history-the distinctive mark, characterizing the historical, racial and national minds, over against the stationary, non-historical and prehistorical ones. The possession of a true, historical self-consciousness requires that the respective national minds should entertain a clear notion of the world at large and of their own individual value to humanity in their pursuit of definite humanitarian aims. All this implies something more than merely a mechanical process or an enumeration of dry sociological statistics, but rather the creative stages of a mental evolution-a long series of repeated unequal efforts, which the nonhistorical races never have made, but which the prehistorical races attempted, at least, to realize during their prehistoric period. It was reserved for the modern science of language to construct a more solid "Science of National Character." From the middle of the past century, German philologists, and German philological reviews, have been collecting a wealth of valuable materials for this purpose, among which latter I may again mention the Zeitschrift für Völkerpsychologic, first edited by the Professors Steinthal and Lazarus.

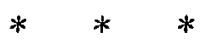

In the above general survey, it was not my intention to give a complete outline of Humboldt's theory of the science of language. This would have required a lengthy investigation of the principles (Grundsätze) of his science of language, and a close analysis of his "speech-idea" (die Sprachidee, or dic Idee der Sprachvollendung), in the elucidating and adjusting of which Dr. Steinthal has performed the arduous task of imparting a higher value to 
Humboldt's original ideas. By this "speech-idea" we do not understand any attainable postulate or absolute "speechideal," but only the speaking-activity of mankind while striving to realize, to create language. The main task of the modern science of language will for a long time still consist in the effort to demolish the dualistic notion of the substantial unity of languagcs. Dr. Steinthal believed that this could be attained by attempting a novel classification of languages, conceived as evolution of the speechidea. In this classification the "kosmos" of articulate sounds, of the "airy tongues" of all the races of the earth, has been distributed into thirteen classes in striking analogy with certain natural sciences.

A. H. Gunlogsen. 